\title{
Las infraestructuras de transporte: buenas prácticas en la recuperación y gestión del patrimonio territorial
}

José Luis Lalana Soto | Dpto. de Urbanismo y Representación de la Arquitectura, Escuela de Arquitectura, Universidad de Valladolid Rita Ruiz Fernández, Francisco Javier Rodríguez Lázaro | Escuela Técnica Superior de Ingeniería de Caminos, Canales y Puertos, Universidad de Castilla-La Mancha

URL de la contribución <www.iaph.es/revistaph/index.php/revistaph/article/view/4957>

\section{RESUMEN}

Las infraestructuras y redes de transporte proyectadas y construidas desde las décadas centrales del siglo XVIII constituyen un patrimonio histórico de enorme relevancia, pero su protección es todavía, en nuestro país, muy limitada. Las escasas propuestas para su recuperación se han centrado en infraestructuras que en el momento de su rehabilitación estaban abandonadas, lo que ha permitido plantear usos alternativos no condicionados por las exigencias derivadas de la necesidad del mantenimiento de la función para la que fueron proyectadas. En ocasiones, estas intervenciones se han traducido en la pérdida de elementos sustanciales, dificultando, en consecuencia, una adecuada transmisión de los valores intrínsecos de la propia obra de ingeniería a sus potenciales usuarios. Este escenario evidencia la necesidad de establecer criterios de actuación que puedan incorporarse a los proyectos de recuperación de este tipo de bienes. El artículo presenta dos propuestas de ámbito internacional -la EN2 portuguesa en el tramo comprendido entre Almodôvar y São Brás de Alportel, y el Ocho del Šargan, en Serbia-, con objeto de evaluar la posibilidad de establecer prácticas que compatibilicen, de forma integrada, la preservación y difusión patrimonial, el mantenimiento de la función transporte, y las estrategias orientadas a la activación turística y el desarrollo socioeconómico de sus corredores.

\section{Palabras clave}

Carreteras | EN2 | Conservación (Patrimonio) | Ferrocarriles | Infraestructuras de transporte | Ingeniería civil | Intervención | Obra pública | Ocho del Šargan | Portugal | Rehabilitación | Serbia | 


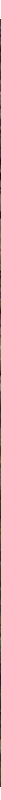

Transport infrastructure: Good practice in the recovery and management of the territorial heritage

\section{ABSTRACT}

The infrastructure and transport networks designed and built as from the mid-eighteenth century constitute historic heritage of enormous relevance. However, the protection of these roads is still very limited, in this country, and the very few conservation proposals that have been made to date, have focused on infrastructure that had been abandoned at the time of restoration. This has allowed repurposing that would have been impossible if the infrastructure had retained its original design purpose. Furthermore, these interventions have occasionally led to the loss of valuable heritage assets, which has handicapped the correct assessment of the intrinsic values of these engineering works by its potential users. This situation demonstrates the need to establish design and intervention criteria that can be incorporated in conservation and restoration projects of these types of assets and, in particular, railways and roads. In this respect, the article presents two international restoration projects -the Portuguese EN2, in the section between Almodôvar and São Brás de Alportel, and the Šargan Eight, in Serbia-in order to raise questions that could serve as the basis for alternative restoration proposals to those traditionally conducted in Spain.

\section{Key words}

Roads | EN2 | Conservation (Cultural heritage) | Railways | Historic transport infrastructure | Civil Engineering | Intervention | Public works heritage | Šargan Eight | Portugal | Rehabilitation | Serbia |

Cómo citar: Lalana Soto, J.L., Ruiz Fernández, R. y Rodríguez Lázaro, F.J. (2021) Las infraestructuras de transporte: buenas prácticas en la recuperación y gestión del patrimonio territorial. Revista PH, n. ${ }^{\circ}$ 104, pp. 126-143. Disponible en: www.iaph.es/revistaph/index.php/revistaph/article/view/4957 DOI 10.33349/2021.104.4957

Enviado: 07/06/2021 | Aceptado: 19/07/2021 | Publicado: 01/10/2021 


\section{INTRODUCCIÓN}

Las infraestructuras y redes de transporte proyectadas y construidas desde las décadas centrales del siglo XVIII constituyen un patrimonio histórico de enorme relevancia (Menéndez de Luarca y Soria 1994; Soria 1997; Martínez 1996, 2003; Navarro 2009, Nárdiz 2014a). Hoy, los restos materiales de estas infraestructuras se asocian a la consideración de la evolución de la ciencia y la tecnología, las transformaciones de las dinámicas de movimiento e intercambio de personas y bienes, o los procesos y lógicas que explican la construcción histórica del territorio.

Sin embargo, la protección de estas vías de comunicación es todavía, en nuestro país, muy limitada, y las aportaciones conceptuales y metodológicas relativas a su identificación, caracterización y valoración apenas se han traducido en la elaboración e instrumentación de textos normativos que permitan su adecuada preservación (Lalana 2012; Lalana y Santos 2016; Nárdiz 2014b; Ruiz, Rodríguez y Coronado 2017).

Por lo demás, la desatención a estos bienes y sus entornos se ha traducido en la pérdida de buena parte de este patrimonio: gran parte de las infraestructuras lineales históricas que han quedado abandonadas están experimentando un progresivo y en ocasiones irreversible deterioro, y las que se mantienen en uso siguen, por lo general, siendo alteradas sin criterios patrimoniales que permitan apoyar adecuadamente las decisiones proyectuales.

Paradójicamente, y cuando existen ya valiosísimos ejemplos de proyectos de rehabilitación de obras de escala nodal -puentes, faros, presas, etc.-, apenas contamos con experiencias de recuperación de infraestructuras y redes de transporte. Además, los escasos proyectos de intervención que se han desarrollado en nuestro país se han ocupado de corredores de mayor antigüedad -piénsese en el Camino de Santiago o la Vía de la Plata (García 1998)-, y apenas se ha atendido a los canales, ferrocarriles o carreteras construidas a partir del siglo XVIII.

1

La recuperación del canal siguió el Plan Regional de ámbito territorial del Canal de Castilla, elaborado con el apoyo del Centro de Estudios Históricos de Obras Públicas y Urbanismo del CEDEX, y aprobado por la Junta de Castilla y León en virtud del Decreto 205/2001, de 02/08/2001
En relación con los primeros, los escasos canales de transporte de cierta longitud construidos en los siglos XVIII y XIX en España declinaron tras la aparición del ferrocarril $y$, aunque afectados por fuertes procesos de deterioro, apenas sufrieron modificaciones. Su abandono ha permitido que, en los proyectos dirigidos a su recuperación, hayan podido plantearse usos alternativos alejados de los originales y ajenos a las expectativas y demandas funcionales para las que se proyectaron. Baste referirse al Canal de Castilla, cuyo proyecto de recuperación sigue siendo hoy, en nuestro país, el principal referente en materia de rehabilitación y refuncionalización de canales históricos ${ }^{1}$. En síntesis, y al igual que en el caso de otros proyectos de ámbito internacional, la intervención consistió en la restauración de algunos de sus elementos singulares -esclusas, 
dársenas, embarcaderos...-, la adecuación de los caminos de sirga para el uso de peatones y ciclistas, y el establecimiento y explotación de embarcaciones de uso turístico en un pequeño tramo del trazado (Guerra 2004).

En el caso de los ferrocarriles, buena parte de la red construida desde mediados del siglo XIX sigue manteniéndose en uso. Las mejoras introducidas a lo largo del siglo $\mathrm{XX}$ afectaron escasamente a los trazados, pero supusieron una profunda transformación de los puentes y viaductos, la superestructura -raíles, dispositivos de operación y explotación, sistemas de electrificación...-, y las instalaciones y espacios de las estaciones. La atención a la dimensión patrimonial de las líneas en uso sigue limitándose a las estructuras y los edificios de viajeros y, como en otros países, las escasas iniciativas que pudieran guardar relación con su valorización y difusión patrimonial han consistido en la explotación fija o estacional de los trazados mediante material rodante histórico con intención turística². Por lo demás, las intervenciones de refuncionalización en líneas abandonadas, convertidas en vías para tráfico no motorizado, han supuesto el desmantelamiento de las vías y, con ello, la pérdida de la legibilidad del patrimonio ferroviario ${ }^{3}$.

Por su parte, la mayoría de las carreteras construidas durante los siglos XVIII y XIX se mantienen, también hoy, en uso. Conservaron su configuración original durante un largo período de tiempo, y no fueron objeto de obras de mejora hasta el período correspondiente a la aparición y primer desarrollo del automóvil. En este sentido, las primeras modificaciones introducidas en la red principal de carreteras consistieron en la extensión de firmes alternativos al macadam, la introducción de peraltes en las alineaciones curvas y la instalación de nuevos dispositivos de contención y señalización vertical, y no fue hasta las décadas de los años cincuenta y sesenta cuando el aumento del parque móvil y la consolidación de la motorización obligaron a introducir mejoras de mayor entidad. Las principales actuaciones consistieron en la regularización y modernización sistemática de las secciones y los firmes, y en la construcción de centenares de variantes y rectificaciones de trazado para evitar el paso por las travesías y por zonas de orografía desfavorable (Rodríguez et ál. 2007). Sin embargo, y salvo en tramos de muy reducida longitud que quedaron abandonados, los trazados rectificados, más o menos transformados, siguen en servicio dando acceso a los terrenos colindantes. Hasta la fecha, y más allá de alguna actuación desarrollada para incentivar la conducción recreativa en trazados de especial interés paisajístico (Zoido 2006), no se ha implementado ningún proyecto para rehabilitar este tipo de infraestructuras en cuanto bienes patrimoniales.

Las páginas que siguen presentan dos proyectos internacionales de rehabilitación -la EN2 portuguesa en el tramo comprendido entre Almodôvar y São Brás de Alportel, y el Ocho del Šargan, en Serbia-, con intención de evaluar la posibilidad de establecer prácticas que compatibilicen, de forma inte-
2

Es el caso del Ferrocarril de Sóller, en Baleares o del Tren dels Llacs, que comunica Lleida con La Pobla de Segur.

3

La refuncionalización de líneas abandonadas para su uso como vías para tráfico no motorizado se concretó en el programa Vías Verdes, iniciado en 1993. Tiene su origen en el programa Tejido Verde, propuesto en el Plan Director de Infraestructuras 1993/2007. Con carácter previo a su puesta en marcha, se elaboró un Inventario de líneas ferroviarias en desuso que permitió identificar y catalogar $7.684 \mathrm{~km}$ de líneas abandonadas (Aycart 2001). 
grada, la preservación y difusión patrimonial, el mantenimiento de la función transporte, y las estrategias orientadas a la activación turística y el desarrollo socioeconómico de sus corredores.

\section{UNA EXPERIENCIA DE REHABILITACIÓN DE CARRETERAS: LA EN2 PORTUGUESA ENTRE ALMODÔVAR Y SÃO BRÁS DE ALPORTEL}

\section{La EN2 y el programa Estradas-Património}

Al igual que en nuestro país, la modernización de la red viaria portuguesa ha comportado, en los últimos años, evidentes beneficios para el tráfico automóvil y, del mismo modo que en España, ha generado impactos de diversa índole en las carreteras o tramos afectados por la construcción de trazados alternativos.

En el sur, el proceso de rejerarquización de la red motivó que, a partir de la década de los años noventa del pasado siglo, la práctica totalidad del tráfico que, desde Faro, discurría por la EN2 hacia Castro Verde, Ferreira do Alentejo y Montemor-o-Novo, para seguir en dirección norte o conectar con Lisboa, pasara a la N125 y la IC1 y, posteriormente, conforme entraron en servicio, a las autopistas A22 y A2/IP1.

La desatención a la conservación de la EN2 en el tramo comprendido entre Almodôvar y São Brás de Alportel, que había conectado tradicionalmente el Baixo Alentejo con el Algarve, planteó, en 1999, la necesidad de intervenir en el trazado. Frente a la adopción de un proyecto convencional de mejora, los responsables del Instituto das Estradas de Portugal, IEP, propusieron una estrategia alternativa, consistente en recuperar la carretera con criterios patrimoniales con objeto de valorizar el propio patrimonio viario y estimular iniciativas de explotación turística beneficiosas para la reactivación socioeconómica del corredor (Teixeira 2003).

La idea fue el germen del programa Estradas-Património, diseñado con intención de extender aquella primera experiencia a otras carreteras de interés histórico, paisajístico y/o patrimonial (Graça y Vasconcelos 2009). Los primeros trabajos del IEP se tradujeron en la redacción del proyecto de recuperación del tramo y la elaboración de un catálogo de carreteras que pudieran ir incorporándose al programa. El proyecto se presentó a los responsables locales en el verano de 1999, y las obras, coordinadas desde la Dirección de Carreteras de Beja, quedaron concluidas en 2002 (Entrevista 2003).

\section{Evolución histórica del tramo}

El trazado del tramo, que corresponde a la ruta tradicionalmente empleada para el tránsito de personas y mercancías desde el interior al sur de Portugal, 
no se consolidó hasta la segunda mitad del siglo XIX. Fue entonces cuando se pavimentó la calzada y se construyeron los primeros puentes.

La carretera no sufrió alteraciones hasta que, tras la creación de la Junta Autónoma de Estradas, JAE, y en paralelo al primer desarrollo del tráfico automóvil, se instrumentaron medidas para la ordenación y modernización de la red viaria portuguesa. Entre 1933 y 1937 se regularizó la sección transversal y se extendió un riego bituminoso, se construyeron los edificios de apoyo necesarios para la conservación de la carretera -casillas de peones camineros, almacenes de material, etc.-, y se instaló un primer dispositivo de elementos de defensa y señalización vertical (Aguiar 2003; Carneiro 2011). La expansión del uso del automóvil y el potencial turístico de la zona hicieron que el tramo alcanzase notables volúmenes de tráfico, consolidándose, mediado el siglo, como parte del gran eje norte-sur -EN2-, que unió Chaves y Faro.

Ya en la década de 1990, la dificultad del trazado se sumó, como se ha señalado, al acondicionamiento y construcción de ejes alternativos más aptos para la circulación de vehículos y, como consecuencia, el eje histórico de comunicación entre el Alentejo y el Algarve pasó a desempeñar una función secundaria en la estructura y explotación de la red.

\section{El proyecto de recuperación: rehabilitación, acondicionamiento y difusión}

El proyecto mantuvo la geometría de la carretera, y consideró, como parte sustancial de la recuperación, la rehabilitación de los elementos que habían transformado la infraestructura tras la aparición del automóvil. No se propuso ninguna rectificación o mejora local, y únicamente se corrigió el trazado de un pequeño número de incorporaciones e intersecciones. Las actuaciones en la sección transversal consistieron en la extensión de una capa de aglomerado en caliente en la banda de rodadura, el acondicionamiento de las cunetas, la renovación de la señalización horizontal y la instalación de los elementos de señalización vertical que se consideraron estrictamente necesarios para garantizar la seguridad de la circulación. El dispositivo de señalización siguió la normativa técnica, y no procuró ninguna similitud formal o cromática con los elementos ya existentes.

Las operaciones de rehabilitación, apoyadas en la documentación histórica disponible, se centraron en los elementos de señalización vertical, los sistemas de contención lateral, una fuente y un mirador, los edificios de conservación y las casillas de peones camineros, y las obras de fábrica.

La señalización objeto de rehabilitación incluyó los indicadores de distancia, las señales de precaución y desvío, y los postes miriamétricos, kilométricos y hectométricos. Las operaciones de restauración se limitaron a la repara-

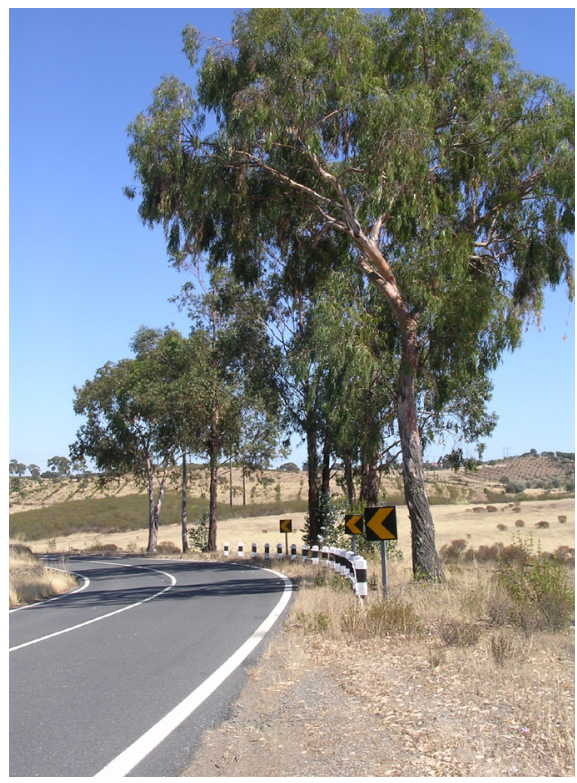

Vista del trazado de la EN2 en Portugal | foto Francisco Javier Rodríguez (2009) 

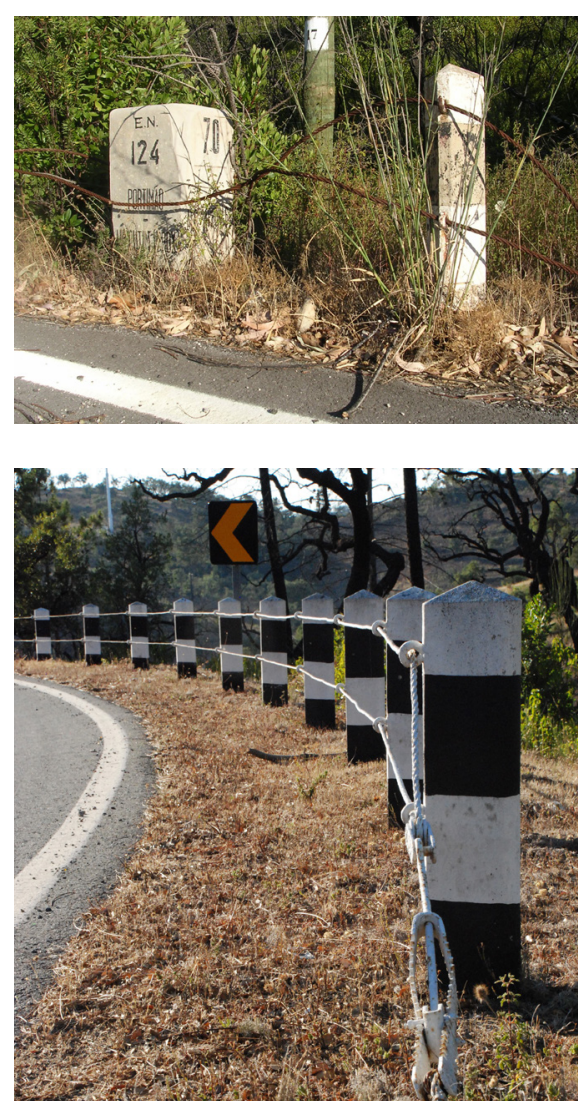

Sistemas de contención antes y después de la rehabilitación | fotos Francisco Javier Rodríguez (2009)

ción de las partes deterioradas y la recuperación de la rotulación y la pintura originales. En algunos casos, los postes más aislados se retiraron de su emplazamiento original y se reubicaron en tramos en los que, junto con los existentes, pudieron establecerse con facilidad secuencias continuas.

La recuperación de los sistemas de contención -mallas metálicas, cables tensados sobre postes de hormigón, montantes y durmientes de hormigón, barreras rígidas curvas-, se concentró en las alineaciones de menor peligro potencial para el tráfico, y los elementos de los tramos retirados que se encontraban en mejor estado de conservación fueron reutilizados para completar los que se rehabilitaron.

Los edificios de conservación y las casillas de peones camineros del tramo fueron asimismo restauradas. La rehabilitación se centró en las fachadas y los elementos exteriores, y el acondicionamiento de los espacios interiores tuvo en cuenta la posibilidad de que los edificios se refuncionalizaran como centros de interpretación o espacios disponibles para actividades y usos locales y turísticos.

El acondicionamiento de las obras de fábrica se circunscribió a la limpieza y la recuperación de las partes enlucidas, la rehabilitación de la señalización existente y la instalación de balizas con objeto de advertir al conductor del estrechamiento de la sección de la calzada. Siguiendo los objetivos perseguidos por el proyecto, no se planteó el ensanchamiento de los tableros o la rectificación de las alineaciones curvas de entrada y salida de las estructuras. Además de los edificios de servicio, se rehabilitaron el mirador de Caldeirão y la fuente de las Bicas da Serra.

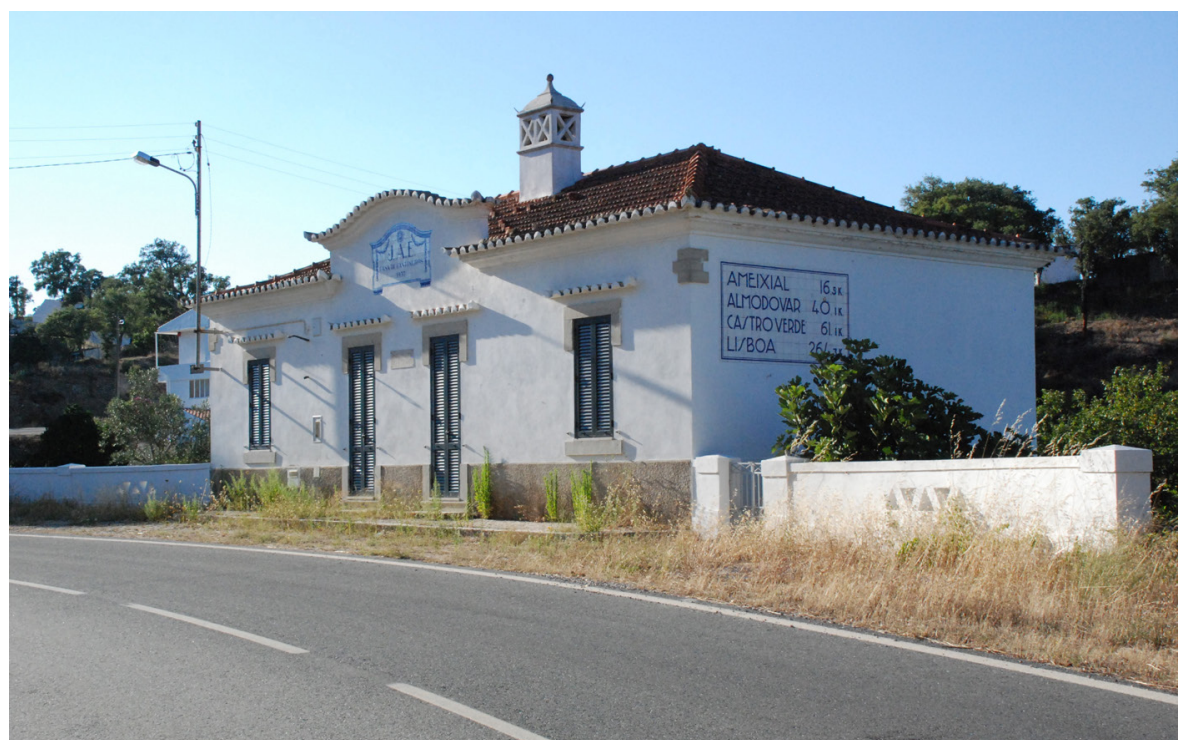


Las obras se completaron con la construcción de tres pequeñas áreas de descanso dispuestas a lo largo del itinerario, y la instalación de dos paneles informativos en los extremos del tramo. Como en el caso de la señalización vertical de acompañamiento, su diseño no buscó ninguna similitud con los elementos rehabilitados.

La difusión del proyecto, y por ende del programa, se concretó en la elaboración de una guía cuidadosamente editada. Además de ofrecer abundante información sobre la evolución histórica de la construcción de la carretera y el propio proyecto de recuperación, el texto y las imágenes exponían, con detaIle, aspectos relativos al paisaje, la fauna y la flora, el patrimonio construido y los usos y costumbres tradicionales característicos del corredor (Aguiar 2003).

\section{Resultados}

En síntesis, la rehabilitación de la EN2 en el tramo comprendido entre Almodôvar y São Brás de Alportel permitió compatibilizar el mantenimiento de la función transporte con la recuperación del itinerario como carretera histórica. Además, y habiéndose concebido como experiencia piloto, pudieron evaluarse la metodología y las estrategias del proyecto, y la viabilidad de su extensión a otras carreteras o tramos. Sea como fuere, y coincidiendo con la conclusión las obras, el IEP integró, en 2002, el Instituto para a Construção Rodoviária, ICOR, y el Instituto para a Conservação e Exploração da Rede Rodoviária, ICERR, convirtiéndose, en 2004, en Estradas Portugal. Las transformaciones a que se alude motivaron cambios en las prioridades del organismo (Carneiro 2011), y el programa Estradas-Património quedó, de hecho, en suspenso.

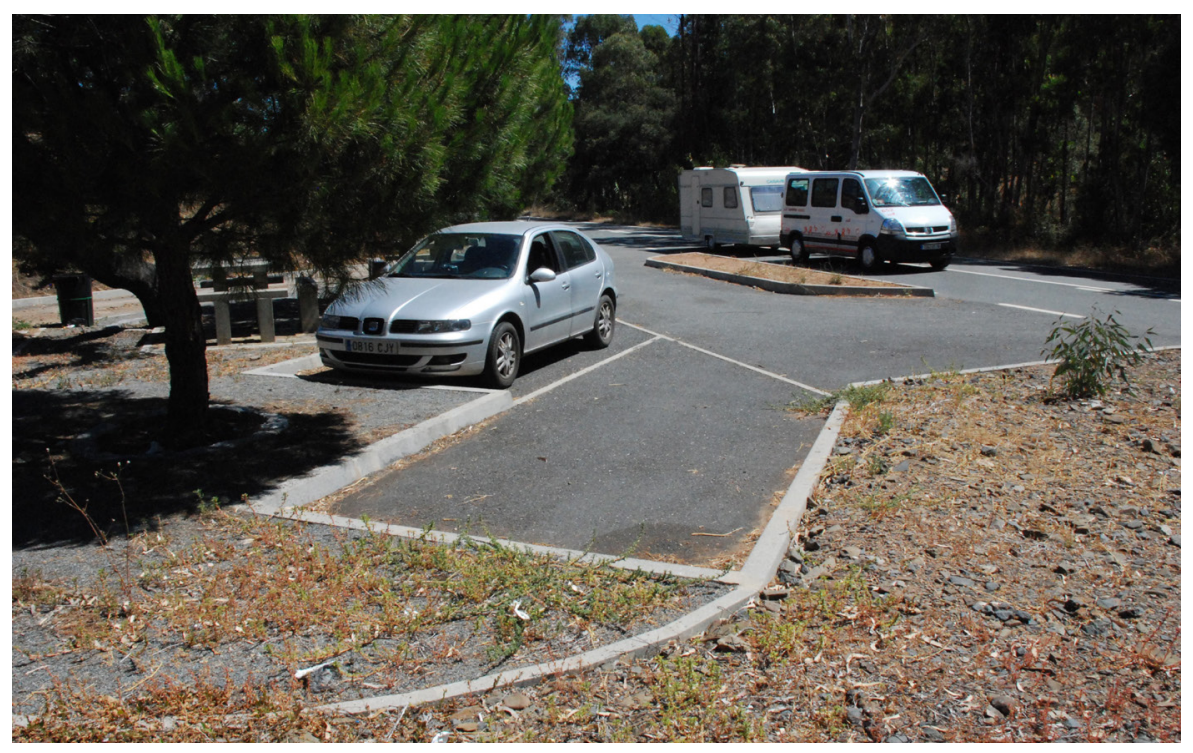

Una de las tres áreas de descanso construidas en los márgenes de la carretera y panel informativo instalado en los extremos del tramo | fotos Francisco Javier Rodríguez (2009)

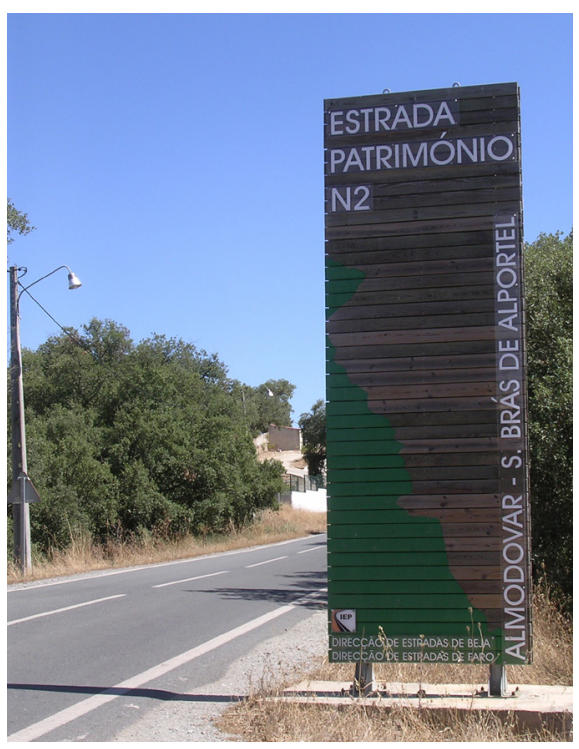


La falta de continuidad del programa y, en consecuencia, de su difusión, se sumó a la escasa implicación efectiva de los municipios que pudieran haberse beneficiado de la iniciativa. No habiendo sido involucrados por la administración central en las fases de propuesta y proyecto, las autoridades y agentes locales quedaron al margen de la toma de decisiones y la asunción de responsabilidades, hecho que contribuyó al desinterés por el mantenimiento y explotación de la carretera histórica como recurso turístico. $\mathrm{Ni}$ las autoridades de Almodôvar ni las de São Brás de Alportel, activas en el esfuerzo por conservar, difundir y rentabilizar su patrimonio histórico, llegaron a asumir la EN2 como parte de semejante patrimonio.

Ya en 2016, los treinta y cinco municipios de paso de la carretera EN2 crearon la Associação de Municipios da Rota da Estrada Nacional 2 y pusieron en marcha el proyecto Rota Estrada Nacional 2. El esfuerzo de la asociación se ha centrado en la consolidación de un producto turístico orientado a la reactivación del corredor, y ha quedado articulado sobre la idea de la "ruta" -no ya de la carretera-, como soporte de actividades y experiencias. En lo que toca a la promoción, el proyecto se ha traducido en estrategias como la señalización del itinerario, el diseño de una imagen de marca, la creación de un pasaporte que puede sellarse en las localidades de paso, o la apertura de una página web en la que el viajero puede recabar información sobre los alojamientos y servicios, la gastronomía, los productos locales o el patrimonio construido y los espacios naturales que pueden visitarse a lo largo de la ruta. Más allá de que al hilo de la iniciativa se hayan recuperado algunas casillas de peones camineros, se mantenga, en algunos tramos, la señalización vertical, o se haya dispuesto un centro de interpretación de la carretera, el interés por su preservación no figura ya entre los objetivos y reclamos centrales del proyecto.

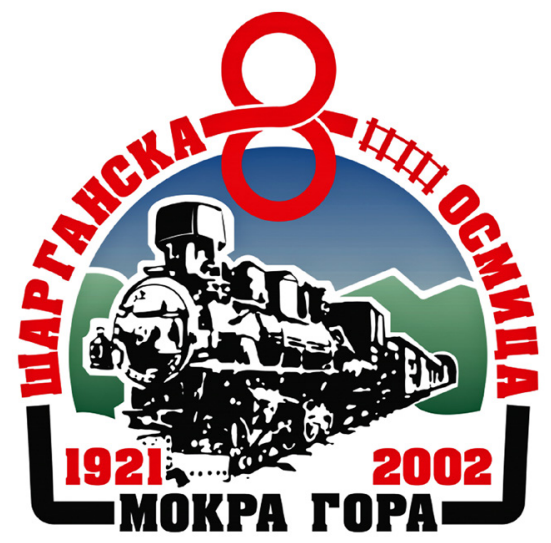

Logotipo comercial del Ocho del Šargan | fuente www.srbvoz.rs/en/nostalgija-2

\section{UNA EXPERIENCIA DE REHABILITACIÓN DE FERROCARRILES: EL OCHO DEL ŠARGAN, EN SERBIA}

\section{El ferrocarril del Šargan}

Este tramo ferroviario está situado en Serbia occidental, muy próximo a la frontera con la República Srpska (Bosnia), y desde 2003 une, a través de un recorrido espectacular de poco más de $15 \mathrm{~km}$, las estaciones de Mokra Gora y Šargan-Vitasi. Es el fruto de una historia que podemos perfectamente calificar de atormentada -antes, durante y después de su servicio comercial activo-, en un territorio y un medio no menos difícil.

El Ocho del Šargan es el nombre comercial por el que se denomina hoy a la parte central de la sección Višegrad-Užice del ferrocarril de vía estrecha, de $760 \mathrm{~mm}$ de ancho, que entre 1924 y 1974 constituyó una de las vías de comunicación de Belgrado con Sarajevo y con el Adriático. 


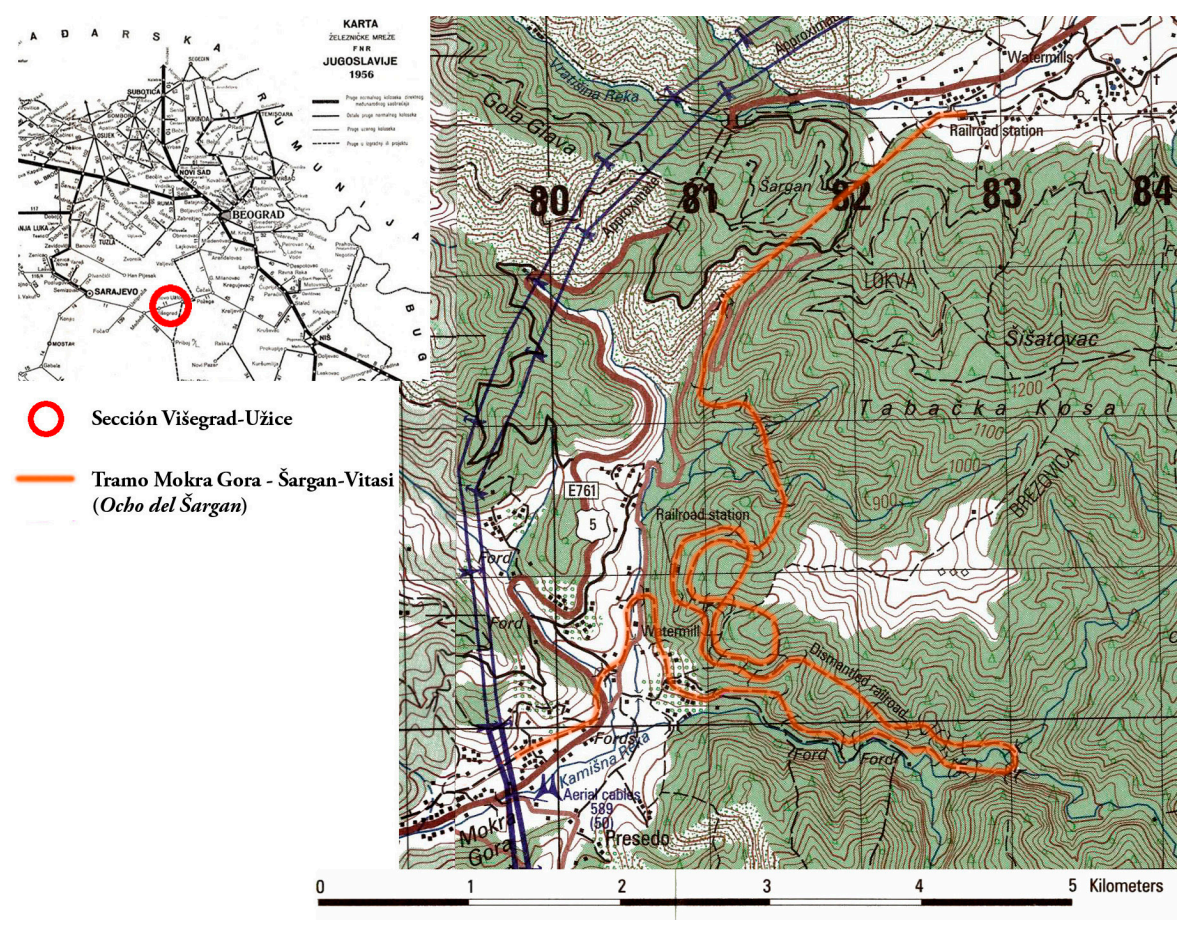

Este tramo fue recuperado por la compañía de los Ferrocarriles Serbios ŽS, Železnice Srbije, que es también la que lo explota actualmente, a través de la compañía estatal Srbija Voz, JSC, que desde 2015 se ha hecho cargo del transporte ferroviario de viajeros.

Dejando aparte los factores históricos y geográficos que dieron origen a su trazado, podemos destacar tres asuntos relevantes por lo que respecta a su recuperación. Primero, que se trata desde el principio de una intervención netamente dirigida al ferrocarril como recurso turístico; segundo, que en la interpretación de esta línea se entremezclan permanentemente cuestiones culturales, naturales, etnográficas o simbólicas, sin apenas distinción entre unas y otras, y en las cuales el patrimonio, en sentido estricto y por lo que se refiere al ferrocarril como infraestructura lineal de transporte, es más un discurso que un criterio fundamental; y tercero, relacionado con los anteriores, que la línea férrea se concibe más como una atracción que como un elemento patrimonial a preservar. En este sentido, cabe señalar que lo que hoy vemos es una reconstrucción, que efectivamente ha respetado el trazado y las obras de paso, y específicamente el ocho que le da nombre, pero la infraestructura llegó a desmantelarse. A propósito del ocho, este trazado helicoidal se trata solo como una curiosidad llamativa, y en ningún momento aparece explicación alguna sobre la importancia de esta configuración -los "lazos"- para superar las rampas en el ferrocarril, o sobre la relación directa que este caso concreto tiene con la sección extraordinariamente estrecha de
Trazado entre Mokra Gora y Šargan Vitasi | plano elaboración propia, utilizando como base el plano de la red ferroviaria de Yugoslavia en 1956 (JŽ Timetable 1956/1957), y las hojas 2982-I (Bajina Basta) y 2982-IV (Višegrad) de U.S. Defense Mapping Agency (1997): Former Yugoslavia Topographic Maps Series M709, 1:50.000 
la vía, que es la que permite radios de curva muy reducidos, aunque sea a costa de imponer una baja velocidad en la circulación.

\section{Evolución histórica de la línea Višegrad-Užice}

Como hemos señalado ya, la materialización de esta sección (VišegradUžice) fue complicada desde sus orígenes. En 1906, el Imperio Austrohúngaro buscó la conexión de Višegrad, a orillas del Drina, con la frontera serbia, llegando en 1916 hasta Mokra Gora, en ese momento con mano de obra compuesta por prisioneros de guerra, fundamentalmente rusos e italianos... pero el paso del Šargan, entre los macizos de Zlatibor y de Tara, que constituye el cierre del valle de Mokra Gora hacia el interior de Serbia, se quedó sin resolver.

En 1921, con el establecimiento del Reino de los Serbios, Croatas y Eslovenos, la conexión entre Belgrado y Sarajevo pasó a ser considerada una cuestión fundamental para el nuevo estado, y se retomaron los trabajos. El acceso de Mokra Gora al Šargan se resolvió con un trazado muy sinuoso, con rampas continuadas del $18 \%$, una veintena de túneles -el más largo de los cuales es el que da acceso a la estación de Šargan Vitasi-, y la configuración del ocho. La conexión con Užice, a unos 35 km del Šargan, permitió reducir extraordinariamente la distancia por ferrocarril entre Belgrado y Sarajevo, que hasta entonces se había resuelto por Croacia. Una solución que, según hemos mencionado, fue posible por el ancho de vía de $760 \mathrm{~mm}$, pero que conllevaba también una limitación en las prestaciones de la infraestructura, tanto en términos de carga transportada como de velocidad. No obstante, hasta la Segunda Guerra Mundial discurrió un tráfico importante por esta línea, tanto de mercancías como de viajeros, y en este último caso se llegaron a implantar, a finales de la década de 1930, automotores diésel para aumentar la velocidad comercial de los trenes de viajeros.

Tras la Segunda Guerra Mundial, en la que esta zona fue un territorio controlado por los partisanos y, por tanto, el teatro de muchas operaciones militares, comenzó la etapa de declive, en la medida en que el nuevo estado de Yugoslavia acometió obras de modernización de la infraestructura, fundamentalmente la integración de una red muy heterogénea, que se unificará adoptando el ancho internacional para las líneas más importantes, y el desarrollo de nuevos trazados para la conexión de Belgrado con Sarajevo -desde 1947, por Vrpolje y Brčko, en Croacia-, y, sobre todo, de Belgrado con el Adriático, a través de Montenegro, con destino en el puerto de Bar. Estas líneas suponían una reducción en los tiempos de viaje y prestaciones muy superiores a las ofrecidas por los diversos tipos de vía estrecha. Así, en 1969, la estación de Užice, que pasó a denominarse Titovo Užice, se reconvirtió al ancho internacional, dentro del nuevo trazado Belgrado-Bar todavía en construcción, y la línea de Višegrad, cuyo ancho no se modificó, 
pasó a ser un ramal por el que circulaban unos pocos trenes de viajeros. En 1974, concluida la nueva línea y aduciendo razones económicas, la sección Višegrad-Užice se cerró al tráfico, y el valle de Mokra Gora, un territorio accidentado y muy poco poblado, perdió su conexión ferroviaria. Quince años más tarde, en 1989, se desmantelaron las vías... y muy poco después estallaría la guerra que condujo a la desaparición de Yugoslavia.

\section{La reconstrucción del tramo de Mokra Gora a Šargan-Vitasi}

Sin embargo, el potencial turístico de esta línea era conocido y se había señalado incluso antes del cierre. A finales de la década de 1990 comenzaron algunos intentos de intervención por parte de algunas asociaciones locales y de amigos del ferrocarril, pero el impulso definitivo se dio en 1999, cuando el Ministerio de Turismo serbio aprobó oficialmente un proyecto de reconstrucción. En colaboración con el Museo de los Ferrocarriles de Belgrado se acometió la recuperación de la línea, como ferrocarril-museo turístico, encargando a Ferrocarriles Serbios tanto la reconstrucción como la operación ${ }^{4}$.

A finales de 2001 se abrió el tramo de Šargan Vitasi a la estación de Jatare pasado el ocho, en la que se encuentra el bar/restaurante para los viajeros-, se reconstruyó la estación de Mokra Gora, y en el verano de 2003 se inauguró el tramo explotado actualmente.

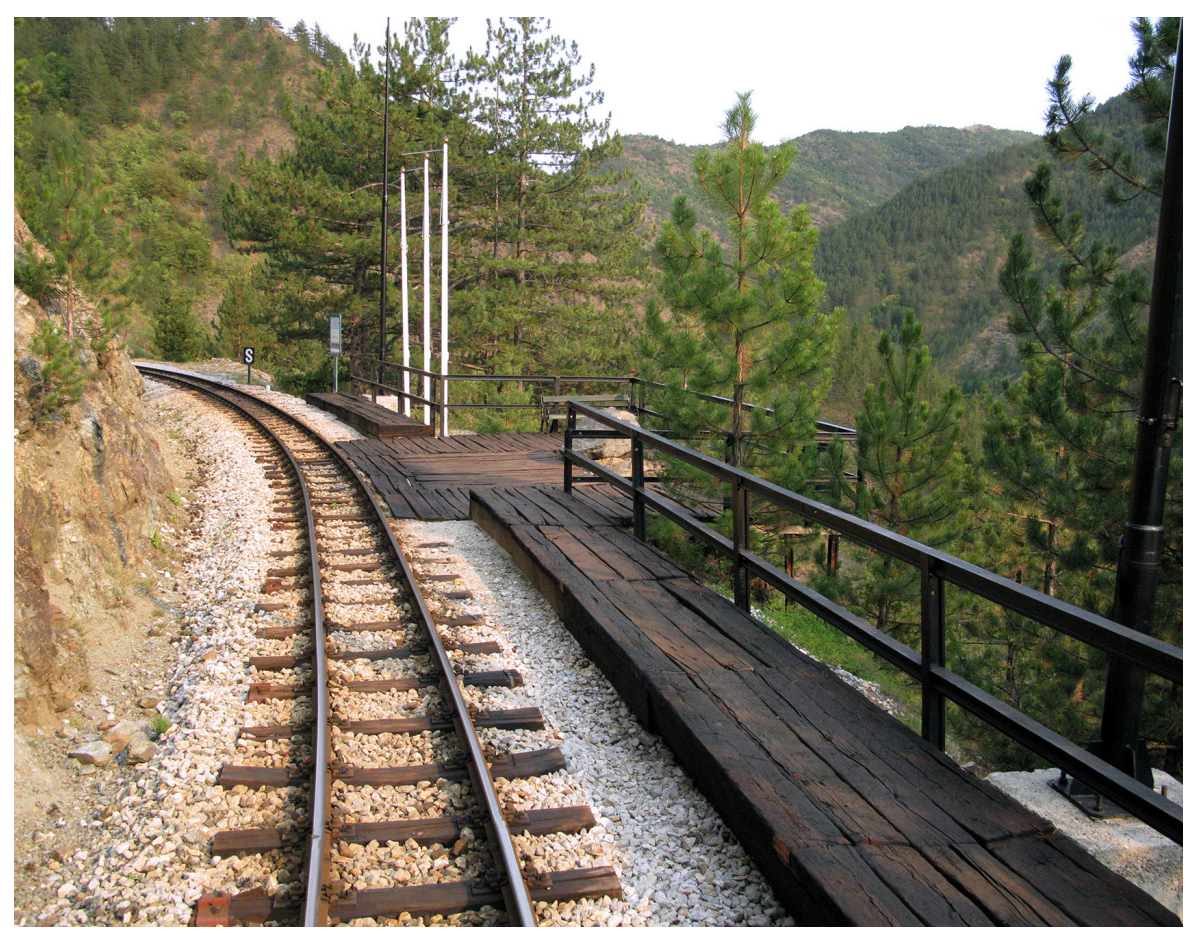

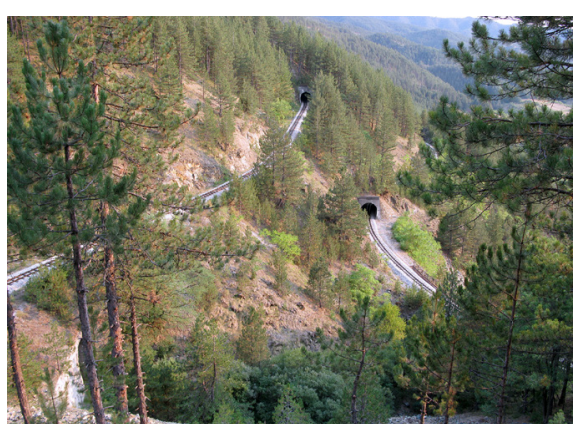

Vista de los túneles del Ocho del Šargan | foto José Luis Lalana (2012)

$$
4
$$

Además de la línea del Šargan, se reconstruyó también un ferrocarril forestal, de 600 $\mathrm{mm}$ de ancho de vía, en el fondo del valle de Mokra Gora, que hoy no se utiliza más que esporádicamente, y que no tiene conexión ferroviaria con el del Šargan.

A lo largo del trazado se instalaron varios miradores, tanto para los pasajeros del tren turístico como para las partes del recorrido que cuentan con un sendero habilitado para caminantes | foto José Luis Lalana (2012) 


\section{Resultados}

Son muchos los aspectos de la explotación que difieren notablemente de los parámetros que tuvo la línea cuando estaba activa, tanto por lo que se refiere al control del tráfico como al material rodante: las locomotoras diésel que remolcan habitualmente el tren fueron importadas de Rumanía, las de vapor, que sí son originales, necesitaron una reconstrucción completa para poder ser puestas en circulación, y los coches provienen de material conservado de otras líneas del mismo ancho de vía. A ello hay que añadir cuestiones como la velocidad, las paradas o la ausencia de problemas de gestión del tráfico, por citar solo algunas. Se llegó incluso a añadir algunos elementos, como es el caso de la estación de Golubići, que se construyó como decorado cinematográfico para la película La vida es un milagro, de Emir Kusturica.

5

Por este proyecto, Emir Kusturica obtuvo en 2005 el Premio Europeo de Arquitectura Philipe Rotthier.

6

El Parque Nacional de Tara y el Cañón del río Drina están incluidos en la Lista Indicativa de Serbia para la Lista del Patrimonio Mundial desde el año 2002.
La figura del músico y director de cine Emir Kusturica está estrechamente ligada a la difusión de este espacio, y de este ferrocarril, puesto que construyó también junto a Mokra Gora, en la colina de Mećavnik, el etno-poblado de Drvengrad $^{5}$, una mezcla de recuperación de arquitectura tradicional, museo etnográfico y hotel de lujo -denominado como la colina-, en el que suelen alojarse personalidades famosas. $Y$ es también el impulsor del festival internacional de cine (y de música) de Kustendorf, que desde 2008 se celebra anualmente.

Por otra parte, la presencia del ferrocarril ha favorecido el desarrollo de otros elementos patrimoniales y turísticos, entre los que cabe destacar el patrimonio natural. El valle de Mokra Gora estuvo incluido como entorno de protección del Parque Nacional de Tara ${ }^{6}$ desde su creación en 1981, pero en 2008 fue declarado el Parque Natural Šargan-Mokra Gora, que abarca una superficie de casi 11.000 hectáreas, una de cuyas principales atracciones es el ferrocarril del Šargan.

Y para concluir esta somera aproximación, el éxito del Ocho del Šargan ha impulsado la recuperación de otras secciones de la línea. Poco después de la inauguración del tren de Šargan, los Ferrocarriles de la República Srpska decidieron acometer la reconstrucción del tramo Mokra Gora-Višegrad, que fue inaugurado en 2010, con la presencia de autoridades serbias y de la República Srpska, aunque actualmente solo circulan por esta vía algunos trenes especiales para grupos turísticos, gestionados por los Ferrocarriles Serbios.

A modo de recapitulación final, podemos calificar los resultados como ambivalentes. En términos de respeto por el patrimonio y por la obra pública, la experiencia se podría calificar como poco valiosa, puesto que no se ha documentado - o al menos no se ha difundido ni se ha utilizado-, la situación pre- 
via a la intervención, no se transmite mensaje alguno en este sentido, y no se ha dudado en añadir elementos, en ocasiones por la evidente necesidad de resolver problemas técnicos de funcionamiento, como es el caso del material rodante, de la reconstrucción de algunas estaciones o la adaptación a una explotación con exigencias muy diferentes de las tradicionales, pero en otros casos sin otro criterio que el pintoresquismo o la creación de ambiente.

No obstante, hay que tener presente que éstos son aspectos que, aunque afectan a las condiciones de autenticidad y de integridad, podrían paliarse mediante mecanismos de interpretación del patrimonio que introdujesen la visión técnica, y con un tratamiento de formas y materiales que identificase claramente qué es lo "original" y qué lo "añadido". Pero, por encima de todo, es un ferrocarril, que funciona como tal ferrocarril y que contribuye significativamente a que se valore, tanto por la población como por los visitantes, lo que una infraestructura histórica puede significar.

Por otra parte, en términos de activación de un área económica y demográficamente deprimida, de visibilización del ferrocarril y de la obra pública, y de catalizador de proyectos territorial y conceptualmente más ambiciosos, no cabe sino señalar su éxito.

Llegados a este punto... ¿cuál de estas consideraciones debería primar para poder denominarlo como una "buena práctica"?

\section{DISCUSIÓN Y CONCLUSIONES}

Definir una buena práctica sin sombras, en una materia tan compleja y multifacética como es la del patrimonio de las infraestructuras lineales de transporte, es sin duda un asunto difícil.

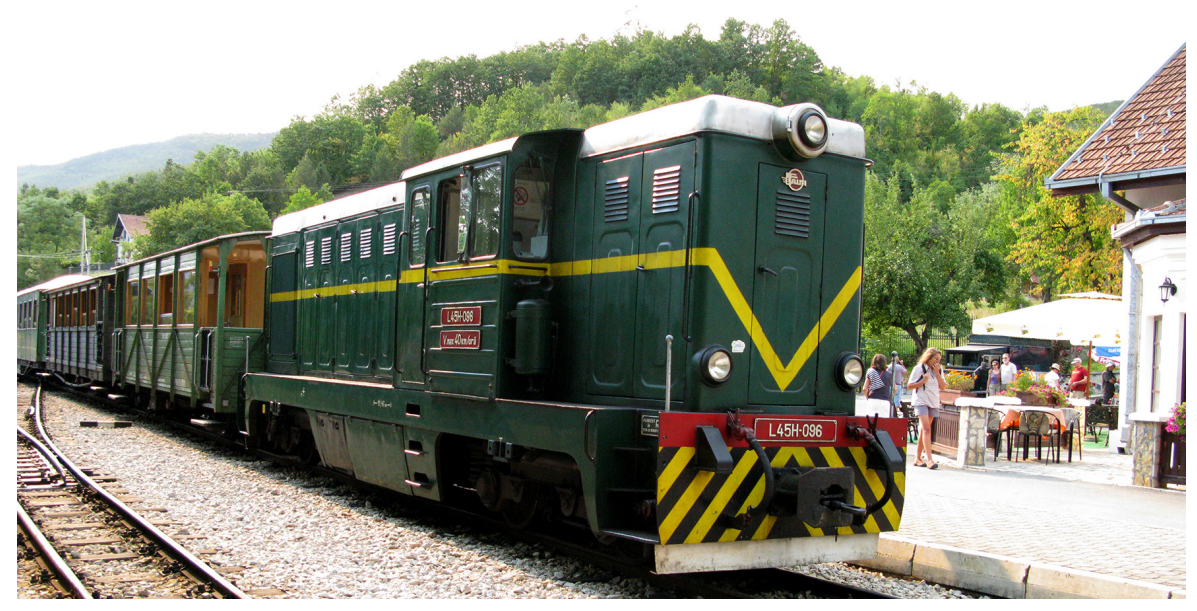

Material rodante. A la izquierda, coches de viajeros y locomotora diésel L45H-096, de origen rumano, en la estación de Mokra Gora. A la derecha, locomotora de vapor 83-052, perteneciente al Museo de los Ferrocarriles de Belgrado, que durante su servicio activo circuló por esta línea y ha sido restaurada funcionalmente. Solo circula en ocasiones determinadas, y habitualmente se expone en la estación de Šargan Vitasi, en una marquesina diseñada al efecto situada junto a las nuevas instalaciones de tracción | fotos José Luis Lalana (2012)

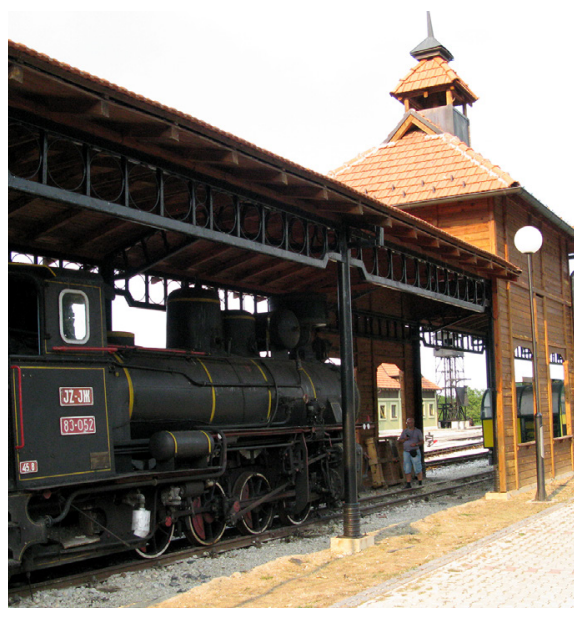


Como queda dicho a propósito de obras como el Canal de Castilla, las escasas propuestas de recuperación de infraestructuras históricas de transporte en nuestro país se han centrado, hasta la fecha, en bienes que en el momento de su rehabilitación estaban abandonados, lo que ha permitido plantear usos alternativos que no han entrado en colisión con las exigencias derivadas de la necesidad del mantenimiento de la función para la que fueron proyectadas.

En ocasiones -es el caso de las vías verdes ferroviarias-, estas intervenciones se han traducido en la pérdida de elementos sustanciales no menos relevantes que los habitualmente considerados valiosos, dificultando, en consecuencia, una adecuada transmisión de los valores intrínsecos de la propia obra de ingeniería a sus potenciales usuarios.

Este escenario evidencia la necesidad de establecer criterios patrimoniales de diseño e intervención que puedan incorporarse a los proyectos de acondicionamiento y recuperación de este tipo de infraestructuras y, especialmente, de los ferrocarriles y las carreteras. En este sentido, los casos de estudio que se han expuesto plantean ideas que pueden servir como base para ensayar propuestas de rehabilitación alternativas a las tradicionalmente desarrolladas en España.

La preservación de obras públicas lineales entraña retos muy diferentes a los que plantea la rehabilitación de las obras públicas históricas que, tradicionalmente, se han concebido como monumentos. Abordar la recuperación patrimonial de un bien territorialmente extenso, y más concretamente de una vía de comunicación, exige trabajar a diferentes escalas, y enfrentarse a elementos de muy diversa índole -desde el trazado o los puentes de mayor envergadura a las pequeñas obras de drenaje o los sistemas de señalización-, que únicamente cobran valor si se conciben como un conjunto. En tal sentido, analizar una obra lineal exige, por una parte, una adecuada comprensión de los contextos urbanos y territoriales y, por otra, entender que las obras singulares -en particular los puentes y viaductos, también las estaciones-, no son en última instancia sino nodos o fragmentos de una determinada infraestructura o red de transporte.

Resulta, asimismo, esencial comprender y valorar la evolución histórica de las infraestructuras cuya recuperación se plantea, y en consecuencia, considerar tanto los elementos que corresponden a su estado inicial como los que las han reconfigurado, produciendo alteraciones de mayor o menor entidad, a lo largo del tiempo. La atención a las transformaciones -nuevos dispositivos y sistemas de señalización y contención, modificaciones de las estructuras, instalaciones y edificios de servicio...-, permitirá interpretar los cambios derivados de las concretas exigencias funcionales de los tráficos que han soportado y documentar las inflexiones que determinan las dinámicas históricas de movilidad. 
En el caso de las infraestructuras lineales que se mantienen en uso -y en particular de las carreteras-, las intervenciones deberán garantizar el mantenimiento de sus condiciones funcionales y de seguridad. La flexibilización de los criterios de diseño y acondicionamiento, adecuados para las vías de alta capacidad pero innecesariamente rígidos para las que soportan tráficos débiles, puede permitir preservar la infraestructura histórica sin desatender aquella exigencia.

Asimismo, resulta necesario evaluar la compatibilidad de los usos turísticos, ya sea mediante la recuperación de antiguo material rodante o fomentando la conducción recreativa, con los estrictamente funcionales. Es esta una cuestión que, aunque fácil de resolver en las carreteras, mediante la instalación de apeaderos y tramos que faciliten las maniobras de adelantamiento, requiere de soluciones más complejas en el caso del ferrocarril. En función de la frecuencia de las circulaciones, y de los sistemas de control del tráfico de la línea, cabría plantear, en todo caso, estrategias orientadas a la habilitación de accesos o espacios que permitan su observación.

En relación con sus potenciales usuarios, debe considerarse el hecho de que, en el caso de la carretera, la circulación automóvil y la presencia de tramos afectados por fuertes pendientes longitudinales dificultan el tráfico de peatones y ciclistas. Por el contrario, el ferrocarril cuenta con las ventajas derivadas de la geometría del trazado y del control de las circulaciones -de velocidades y con frecuencias previsiblemente reducidas-, lo que hace más factible la instalación de bandas laterales en los márgenes de la plataforma. Sea como fuere, y aun tratándose de líneas abandonadas, parece oportuno conservar los elementos característicos de la superestructura con objeto de no comprometer el valor patrimonial de la obra de ingeniería?.

Por lo que hace al impacto territorial, la recuperación de cualquiera de estas infraestructuras puede constituir una oportunidad para incentivar la afluencia de visitantes a zonas rurales habitualmente deprimidas y en riesgo de vaciamiento. No obstante, la experiencia aconseja implicar a las autoridades y agentes locales de las poblaciones próximas a la infraestructura en las fases de planeamiento y proyecto para asegurar así un adecuada conservación, explotación y promoción de la obra como recurso turístico.

Por último, y de la misma manera que se ha planteado en el caso de otros patrimonios menos reconocidos, la recuperación de infraestructuras lineales históricas debería ir acompañada de una labor didáctica y de gestión, hasta ahora escasamente atendida, encaminada al reconocimiento y valoración de la obra de ingeniería, de las formas históricas de movilidad y de la propia función transporte.
7

Como se ha hecho en la reciente intervención del tramo final de la línea Boadilla-Barca d'Alva, la única declarada BIC en España, entre la estación internacional de La Fregeneda y el Puente Internacional sobre el río Águeda. Una interesante solución de compromiso entre la comodidad del recorrido para los visitantes, la fidelidad a su valor patrimonial como infraestructura lineal ferroviaria y la preservación del entorno.

\section{Agradecimientos}

Esta publicación se enmarca dentro del proyecto nacional de investigación financiado por el Ministerio de Ciencia, Innovación y Universidades que, liderado por la Rita Ruiz, tiene como título Análisis y definición de estrategias para la caracterización, recuperación y puesta en valor del patrimonio de las obras públicas. Una aproximación desde la escala territorial (PID2019105877RA-I00). 


\section{BIBLIOGRAFÍA}

- Aguiar, A. (coord.) (2003) Estradas-Património. EN2. Almodôvar-S. Brás de Alportel. Da Planície Alentejana ao Barrocal Algarvio. Lisboa: Instituto das Estradas de Portugal

- Associação de Municípios da Rota da Estrada Nacional 2 (2021) A estrada que nos une. Disponible en: https:// www.rotan2.pt/ [Consulta: 31/05/2021]

- Aycart, C. (2001) Vías Verdes, reutilización de ferrocarriles en desuso para movilidad sostenible, ocio y turismo. Informes de la Construcción, n. ${ }^{\circ} 475$, pp. 17-29

- Carneiro, M.I.S. (2011) As casas dos cantoneiros do Algarve: da conservação das estradas a património a conservar. Tesis de maestría inédita. Universidade Aberta Lisboa. Disponible en: https://repositorioaberto.uab.pt/bits tream/10400.2/1821/2//\%20Volume.pdf [Consulta: 01/01/20 21]

- Entrevista. Prof. António Lamas. Estradas-Património. Não podem ser "atropeladas" pela pressa da modernidade (2003) Pedra \& Cal, n. o 19, pp. 8-11 Disponible en: http://www.gecorpa.pt/Upload/Revistas/Rev19_Art02.pdf [Consulta: 20/07/2021]

- Ferrocarril de Sóller (2021) Disponible en: http://trende soller.com/ [Consulta: 31/05/2021]

- García, J.L. (1998) Documentación, problemas de conservación, planeamiento urbanístico, rehabilitación y experiencias sobre el patrimonio histórico en el Camino de Santiago y en la Ruta de la plata. En: AA.VV. Patrimonio cultural y sociedad: una relación interactiva. Curso celebrado en Valladolid, del 21 al 29 de marzo de 1997. Valladolid: Junta de Castilla y León; Consejería de Educación y Cultura, pp. 227-266

- Generalitat de Catalunya (2021) Tren dels Llacs. Disponible en: https://trendelsllacs.cat/ [Consulta: 31/05/21]

- Graça, P. y Vasconcelos, T. (2009) Estradas-Património. Conceito e Concretização em Portugal. s.l.: Estradas de Portugal, S.A.; Gabinete do Ambiente

- Guerra, R. (coord.) (2004) El Canal de Castilla: un plan regional. Valladolid: Junta de Castilla y León, 2 vol.

- JSC Serbian Railways (2021) Disponible en: http://serbian railways.com/ [Consulta: 25/05/21]

- JSCSerbianRailways(2021)MuseumandTouristRailways "Shargan Eight". Disponible en: http://serbianrailways. $\mathrm{com} /$ museum-and-tourist-railways-shargan-eight/ [Consul ta: $25 / 05 / 21$

- Nature Park "Šargan-Mokra Gora" (2021) Disponible en: http://www.parkprirodemokragora.org/index.php/en [Consulta: 27/05/21]

- Lalana, J.L. (2012) Los ferrocarriles y el patrimonio mundial. Del monumento al paisaje cultural. En: VI Con greso de Historia Ferroviaria. Vitoria 2012. Del 5 al 7 de septiembre.Disponibleen:http://www.docutren.com/Historia Ferroviaria/Vitoria2012/pdf/6046.pdf [Consulta: 20/07/2021]

- Lalana, J.L. y Santos, L. (2016) Retos metodológicos en el estudio, evaluación y tratamiento del patrimonio ferroviario. En: Actas del VI Congreso de Conservación del Patrimonio Industrial y de la Obra Pública en España. Gijón: Cicees, pp. 125-132

- Martínez, R. (1996) Los canales españoles. OP, n. ${ }^{\circ}$ 40 , pp. $52-63$

- Martínez, R. (2003) El patrimonio de las obras públicas. Revista de Obras Públicas, n. ${ }^{\circ} 3.438$, pp. 79-82

- Melo, L. (2003) Lanço da EN 2, Almodôvar e São Brás de Alportel. Recuperação da 1. ${ }^{a}$ Estrada-Património Portuguesa. Pedra \& Cal, n. ${ }^{\circ} 19$, pp. 12-13. Disponible en: http://www.gecorpa.pt/Upload/Revistas/Rev19 Art03.pdf [Consulta: 20/07/2021]

- Menéndez de Luarca, J.R. y Soria y Puig, A. (1994) E territorio como artificio cultural. Corografía histórica de Norte de la Península Ibérica. Ciudad y Territorio. Estudios Territoriales, vol. II, n. ${ }^{\circ}$ 99, pp. 63-93. Disponible en: https://recyt.fecyt.es/index.php/CyTET/article/view/83925 [Consulta: 20/07/2021]

- Nárdiz, C. (2014a) El patrimonio de las obras hidráulicas. En: Obras Hidráulicas de la Ilustración. Catálogo de la exposición (10 de julio-30 de octubre de 2014). Madrid: CEHOPU/Ministerio de Fomento, pp. 55-63

- Nárdiz, C (2014b) El discurso patrimonial de los ingenieros de caminos. Revista de Obras Públicas, n. ${ }^{\circ}$ 3.599, pp. 51-62

- Navarro, J.R. (2009) Pensar la ingeniería: antología de textos de José Antonio Fernández Ordóñez. Madrid: Colegio de Ingenieros de Caminos Canales y Puertos/ Fundación Juanelo Turriano

- Rodríguez, F.J., Coronado, J.M., Ruiz, R. y Vega, J.G. de la (2007) Análisis y valoración del patrimonio histórico de las carreteras españolas, 1748-1936. Madrid: CEHOPU/ CEDEX (Cuadernos de investigación del CEHOPU; 2)

- Ruiz, R., Rodríguez, F.J. y Coronado, J.M. (2017) Modern Roads as UNESCO World Heritage Sites: framework and proposals. International Journal of Heritage Studies, vol. 23, n. ${ }^{\circ} 4$, pp. 362-374. Disponible en: https://doi.org/10.108 0/13527258.2016.1277774 [Consulta: 20/07/2021]

- Šarganska The Shargan 8 (2021) Disponible en: http:// www.sarganskaosmica.rs/ [Consulta: 27/05/2021]

- Soria, A. (1997) Una visión territorial del patrimonio de las obras públicas. La red peninsular de parques lineales históricos. $O P$, n. ${ }^{\circ} 40$, pp. $28-37$ 
- Srbija Voz JSC (2021) Nostalgija. Disponible en: https:// www.srbvoz.rs/en/nostalgija-2/ [Consulta: 27/05/2021]

- Teixeira, E.N. (2013) Manual para a recuperação de Estradas Património. Tesis de maestría inédita. Universidade de Trás-os-Montes e Alto Douro, Vila Real. Disponible en: http://docplayer.com.br/46741579Manual-para-a-recuperacao-de-estradas-patrimonio.html [Consulta: 01/01/2021]

- Tourist Resort Mećavnik-Drvengrad (2021) Disponible en: https://mecavnik.info/en/ [Consulta: 27/05/2021]

- Zoido, F. (2006) Paisaje e infraestructuras, una relación de interés mutuo. Carreteras: revista técnica de la Asociación Española de la Carretera, n. ${ }^{\circ} 150$, pp. 190-199 